\title{
Quality control of immunological veterinary medicinal products in Europe
}

\author{
Katarzyna Pasik, Ewa Łysiak \\ Department of Veterinary Pharmacy, \\ National Veterinary Research Institute, 24-100 Puławy, Poland \\ katarzyna.pasik@piwet.pulawy.pl
}

Received: July 22, 2019

Accepted: November 28, 2019

\begin{abstract}
Medicinal products in Europe are under the strict control of many organisations headed by the European Directorate for the Quality of Medicines and HealthCare (EDQM) in Strasbourg and its related General European Official Medicines Control Laboratories (OMCLs) Network (GEON). The EDQM works in cooperation with the European Medicines Agency (EMA) and the World Health Organisation (WHO). All of these institutions have one main goal - to protect public health in Europe and around the world. One of the more important effects of the harmonisation of pharmaceutical law in Europe was the introduction of the mutual recognition principle for the Official Control Authority Batch Release (OCABR)/Official Batch Protocol Review (OBPR) certificates in the European Union. The National Veterinary Research Institute (NVRI) in Poland is an example of an OMCL laboratory within the Veterinary Batch Release Network (VBRN) that issues the European certificates. The NVRI is actively involved in the batch release of immunological veterinary medicinal products (IVMPs), with approximately 1,800 certificates for IVMPs issued per year. It is also one of only four veterinary OMCLs that perform Post Marketing Surveillance (PMS) studies including approximately 47 IVMPs per year. All the results of the testing data are sent to the Chief Veterinary Officer, and also to the electronic Network platforms of the EDQM, which enables transparent information exchange.
\end{abstract}

Keywords: EDQM, EMA, OMCL, GEON, National Veterinary Research Institute, Poland.

\section{Introduction}

Medicinal products in Europe are subject to rigorous assessment during registration, marketing authorisation, and introduction to the European Union market. The basic criterion that determines the status of drugs is their quality, which is defined by the appropriate strength, effectiveness, safety, stability, and many other biological and physicochemical parameters. There are four marketing authorisation procedures for medicinal products in the European Union: the national procedure, mutual recognition procedure (MRP), decentralised procedure (DCP), and central procedure. The national procedure is used to authorise a medicinal product only in one member state. In Poland, the Office for Registration of Medicinal Products, Medical Devices, and Biocidal Products based in Warsaw is the organisation that issues the marketing authorisations for a national procedure. The MRP procedure can be used if the medicinal product has already been authorised in one of the EU countries or a member state of the European Free Trade Association (EFTA). This procedure consists in the fact that the countries concerned accept the marketing authorisation issued under the national procedure in the reference country (the country in which the product was authorised during the national procedure) (9). At the end of the MRP procedure, national marketing authorisations are issued in all countries concerned. The DCP procedure is intended for the simultaneous registration in more than one EU country of a medicinal product that is not subject to a mandatory central procedure and has not yet been approved in an EU country. The central procedure is applied in the case of a medicinal product to be introduced in all EU countries and Iceland, Liechtenstein, and Norway. This applies to four groups 
of medicinal products: A - those used in humans in the treatment of malignant tumours, HIV/AIDS, diabetes, autoimmune diseases, and other immune dysfunctions, viral diseases, and neurodegenerative diseases; B drugs produced in biotechnology processes; $\mathrm{C}$ - drugs used in advanced therapy, such as gene therapy; D orphan drugs used in rare diseases in humans.

For the central procedure, the European Medicines Agency (EMA) located in London deals with the authorisation of medicines in the European Union. The EMA protects human and animal health by assessing medicines and monitoring their safety within the EU and the European Economic Area (EEA). Pharmaceutical companies apply to it for a marketing authorisation for a given medicinal product, and such authorisations take the form of licenses issued by the European Commission. In such cases, companies may introduce a medicinal product to the market throughout the EU as well as in EEA countries $(13,14)$. After a product receives its admission to trade, a batch may be placed on the market only after receiving a quality certificate from one of the European quality control laboratories - an Official Medicines Control Laboratory (OMCL). The coordination of OMCL activity is the responsibility of the European Directorate for the Quality of Medicines and HealthCare (EDQM), which is part of the Council of Europe and is integrated with the structure of supervision of the quality of medicines and the protection of public health as shown in Fig. 1.

\section{The European Directorate for the Quality of Medicines and HealthCare (EDQM)}

The EDQM was established in 1964 to harmonise quality standards for safe medicines on the European continent and beyond (in addition to member states there are 28 observers, including the WHO) (10). A network of over 700 experts focuses on developing standards for pharmaceutical quality control. After half a century of activity, the EDQM has introduced over 3,000 standards, described in the pages of the European Pharmacopoeia. Nowadays, over $80 \%$ of active substances on the EU market are produced in countries outside Europe and the USA (7). Addressing this situation, the EDQM has developed a special programme for quality control of medicinal products to be able to have oversight of these extra-European products. Systems have been created of certificates granted to the producer which are guarantees for both national authorities and buyers (doctors, patients, and breeders) and proofs that these medications are controlled by the standards of the European Pharmacopoeia. In 1994, the General European OMCL Network (GEON) coordinated by the EDQM was established (14). The EDQM is involved in many international cooperation projects, such as the International API Inspection Programme coordinated by the European Medicines Agency (Table 1). It also participates in global harmonisation initiatives, for example the WHO-instigated development of "Good Pharmacopoeial Practices" (GPhP), which in the future may lead to cooperation between pharmacopoeias around the world. In addition, the EDQM monitors, distributes, and establishes WHO international standards for International Chemical Reference Substances (ICRS) and antibiotics (ISA) (17). The EDQM is the organiser of various experimental studies that bring together laboratories operating in the European Union, which are also a source of many valuable publications. The articles on the analysis of six EU laboratories regarding hepatitis A vaccines are an example of recent research $(21,23)$. The EDQM also co-organises scientific research with the WHO, thereby providing a bridge between Europe and the rest of the world for science concerning medicines. Recently, 14 laboratories from Europe, North America, and Asia participated in such studies regarding the calibration of pertussis toxin BRP batch 1 in a standardised CHO cell-based clustering assay (20). Some European Union countries have begun implementation of the EDQM standards in their legislation, one example being Germany, where a nationally uniform treatment plan has been introduced using the EDQM standards in the context of e-health. Research was carried out in which different coders mapped a list of pharmaceutical dose forms provided in the specification to the standard terms of the EDQM (24). The EDQM has also supported activities related to the detection of illicit drugs since 2005 to assist national law enforcement agencies, and to this end it has introduced information and discussion platforms for European laboratories in the field of testing for falsified drugs (27).

Table 1. Objectives of the EDQM

\begin{tabular}{ll}
\hline 1 & Protection of public health \\
\hline 2 & Introduction of European Pharmacopoeia quality standards \\
\hline 3 & $\begin{array}{l}\text { Surveillance, controlling of medicines - centrally authorised } \\
\text { products (CAP) sampling, market surveillance studies } \\
\text { (MSS), active pharmaceutical ingredients (APIs) }\end{array}$ \\
\hline 4 & $\begin{array}{l}\text { Assurance of quality of blood transfusion and transplantation } \\
\text { products }\end{array}$ \\
\hline 5 & Assurance of quality of cosmetics and food-contact materials \\
\hline
\end{tabular}

The General European OMCL Network and Official Medicines Control Laboratories

The GEON is the network of OMCLs. After medicinal products are released onto the UE market, a network of over 70 OMCLs in over 40 countries verifies their quality by performing control testing and thus provides assurance of the high quality of medications on the European market (14). An OMCL is 
a public institution which performs laboratory testing of medicinal products (both human and veterinary) on behalf of competent authorities. The OMCL also fulfils other state duties, independently from Marketing Authorisation Holders (MAH) or the manufacturers. Research is carried out in the interest of official market surveillance of medicinal products in relation to the safety of humans and/or animals, prior to and/or after marketing of the respective medicines (Table 2, Table 3). Such testing must be free from conflict of interests and should be performed independently and with no role for those who have been involved in the development process, so it expands scientific knowledge of a medicinal product.

Table 2. Objectives of the OMCL

\begin{tabular}{ll}
\hline 1 & Quality control of medicinal products before and after placing on the market \\
\hline 2 & Protection of public and animal health \\
\hline 3 & $\begin{array}{l}\text { Expert assessment in the evaluation of the qualitative part of the registration dossier regarding the admission of } \\
\text { medicinal products to the market }\end{array}$ \\
\hline 5 & Analysis of drugs used illegally or falsified drugs \\
\hline 6 & Pharmacovigilance support \\
\hline 7 & $\begin{array}{l}\text { Participation in the development of the European Pharmacopoeia, monographs and/or general chapters and } \\
\text { methods and the elaboration of reference standards }\end{array}$ \\
\hline 8 & Participation in the Biological Standardisation Programme \\
\hline 9 & Research carried out as part of cooperation with OMCL \\
\hline
\end{tabular}

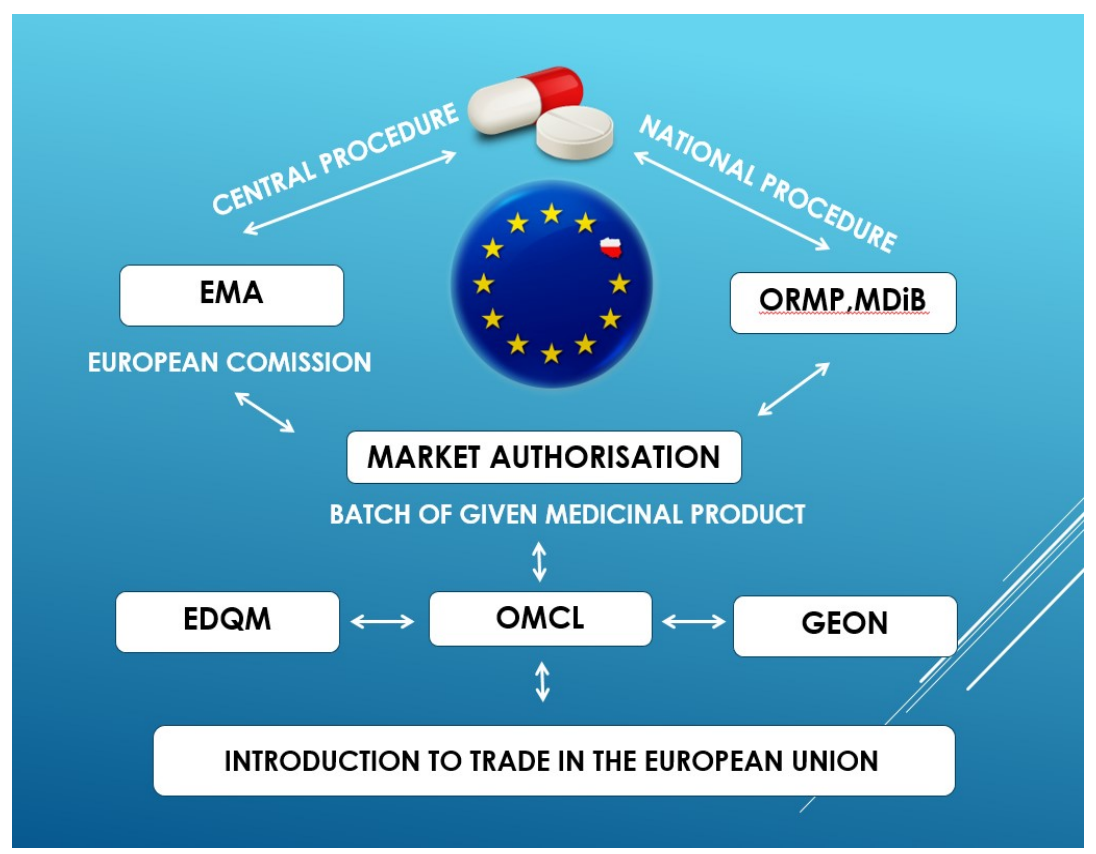

Fig. 1. Diagram of the authorisation and introduction of a medicinal product in the European Union

Table 3. Objectives of GEON

\begin{tabular}{ll}
\hline 1 & Mutual recognition (in UE) of tests performed by OMCLs at the national level \\
\hline 2 & Increase of communication among the OMCLs (e.g. handbooks, databases), work sharing \\
\hline 3 & Harmonisation of working methods (e.g. quality management system, proficiency testing programme, audits) \\
\hline 4 & Coordination of OMCLs work (e.g. collaborative studies on the validation of methods) \\
\hline 8 & Exchange of information \\
\hline 9 & Cooperation with other institutions in the world \\
\hline 10 & Promotion of the development of harmonised standards \\
\hline
\end{tabular}


One of the biggest benefits of being a member of the General European OMCL Network as an OMCL is the access to full information about the activities performed by other laboratories with this status. OMCLs exchange experiences through the OMCL inventory database, containing information available only to network members. A forum in the database is one of the possibilities for discussion on research topics. In addition, every year, representatives of all OMCLs of the GEON network meet at a joint conference. During such conferences, representatives of each laboratory report on their activity for the last year of work in the OMCL ambit. The EDQM also organises training workshops concerning both technical and quality issues. Information also accessible by those from outside the GEON group and the general public is available on the EDQM website (12). GEON also appoints working groups of individual OMCL employees for specific tasks, a notable one of which was the establishment of a special OMCL Counterfeit/Illegal Medicines Working Group in 2011, which coordinates all activities related to training programmes, symposia, or the development of common documents. This activity aims to strengthen the GEON network to prevent the trading of illegal drugs (25).

There are two cooperation zones within GEON (Table 3). The first category is general activities that are open to all member states and observer countries of the European Convention on the Elaboration of a European Pharmacopoeia (e.g. the QA (quality assurance) Programme, the general MSS (market surveillance scheme), the PTS (proficiency testing scheme) studies, educational activities, applied analytical research, and standardisation development. The second category of cooperation concerns only countries from the EU and the European Economic Area (EEA) and encompasses the Centrally Authorised Products (CAP) Sampling and Testing Programme, the MRP and DCP Testing Programme, the Postmarketing Surveillance (PMS) Scheme, the Official Control Authority Batch Release (OCABR) for human biological medicinal products, and OCABR and Official Batch Protocol Review (OBPR) for immunological veterinary medicinal products (IVMPs) (11).

\section{VBRN and IVMPs control}

The OMCL Network includes the Veterinary Batch Release Network (VBRN) that consists of OMCL laboratories performing testing of IVMPs. It is the main forum for the confidential exchange of technical and quality information concerning these products, and that is very important in the regulatory chain. There is an annual meeting of the VBRN network representatives to discuss problems related to the functioning of the Network and to report on the activities of laboratories for the previous year. Such meetings give an opportunity to adopt the VBRN procedures and guidelines and to discuss the needs for product control. The VBRN activity is supervised by the Advisory Board, consisting of four representatives from different members of GEON, elected by their representatives for a four-year term. VBRN activity is closely bound up with assurance of the highest quality of products, which is the foundation of public and animal health protection.

Immunisation of a high percentage of animals in the population stimulates the immunity of the entire herd; the effectiveness of the procedure is confirmed by numerous studies $(6,8,16,19)$. An IVMP is a preparation containing microorganisms whose administration to the body stimulates the immune system to defence. The use of vaccines is the most effective way to prevent infectious diseases (25), and they have led to global victories over many diseases that cause epidemics, such as smallpox, polio, measles, tetanus, tuberculosis, diphtheria, plague, pertussis, typhus, rabies, cholera, and many other diseases that previously decimated human communities. There are many types in the classification of vaccines, depending on the immunoprophylaxis strategy capable of inducing an immune response. Some are vaccines that contain inactivated microorganisms, immobilised due to physical and chemical factors, for example some rabies or influenza vaccines (26). In contrast, attenuated vaccines are those that contain live, attenuated microorganisms with minimised virulence. In terms of the type of microorganisms used, the vaccines are divided into viral and bacterial groups. Vaccines are categorised by the number of antigens and microorganisms present in the product into a monovalent group (containing pathogenic antigens of one type and thus immunising against one disease), a polyvalent group (containing up to several subtypes of antigen of the same pathogenic microorganism and immunising against one infectious disease caused by various serotypes of pathogenic microbe), or the combined vaccine group (simultaneously immunising against several infectious diseases). Because of the route of administration, the vaccines are divided into three other groups: administered by injection (intramuscular or subcutaneous), orally, and inhaled (22). Modern techniques of biotechnology and genetic engineering facilitate an innovative approach to controlling induction of immunity. Nowadays, advanced research is being carried out on the use of the following new types of vaccines: live recombinant vaccines, fusion proteins, anti-idiotype antibodies, synthetic peptide vaccines, and vaccines containing nucleic acids (10). Unfortunately, despite many years of experience in the development of vaccines, evident among other ways in their classification types, effective vaccines against diseases such as cancer have still not been developed. One of the most important goals of $21^{\text {st }}$-century immunoprophylaxis is the construction of an effective anti-cancer vaccine. It is maybe only a matter of time until the cancer vaccines are conferred 
the status of immunotherapeutics. Cancer vaccines based on neoantigens may become commonplace, and clinical trials using cancer immunotherapy have recently shown tremendous therapeutic potential (17).

All of the vaccines that are already commercially available on the market must be examined to ensure their quality.

\section{NVRI as a full member of GEON}

Since January 2017, the National Veterinary Research Institute (NVRI) in Puławy, Poland, has been a member of the prestigious GEON community. The NVRI was established in 1945 as a research and development unit of the Ministry of Agriculture and Rural Development. In 2003, it became a state research institute. Having a background of many scientific and research activities in the field of animal health protection, the NVRI has been involved in batch release and market surveillance studies (MSS) of IVMPs for many years. Nowadays, the NVRI performs vaccine testing as a full member of GEON. In 2018, there were 96 employees involved in OMCL activity within 11 different research teams. The OMCL structure also includes the Center for Maintenance of Experimental Animals, a coordinating team for research and circulation of documentation and the EDQM relations team. The facilities of the OMCL are located in a building refurbished in 2008. All the departments of the NVRI, including the Department of Veterinary Pharmacy, operate under a PN-EN ISO/IEC 17025:2005+Ap1:2007 management system (PN-EN ISO/IEC 17025:2018-02 is in the process of implementation). The main role of the NVRI as the OMCL is primarily the batch release of IVMPs as well as the control of veterinary vaccines that are already on the market.

\section{Batch release of immunological veterinary medicinal products (IVMPs) in the NVRI}

Batch release of an IVMP means a monitoring test of each batch of manufactured product, carried out before placing it on the market, in accordance with article 2 point 9 of the Pharmaceutical Law (3). Based on this, the NVRI is responsible for batch release of IVMPs and, entitled by EDQM attestation, issues national as well as OCABR and OBPR certificates concerning the IVMPs evaluated on the basis of Article 82 of Directive 2001/82/EC amended by Directive 2004/28/EC of the European Parliament and the Council $(4,5)$. OCABR performed by any OMCL must be mutually recognised by all OMCLs from other member states. A shortlist of IVMPs for which a restricted test list for OMCLs has been agreed and which require an OCABR certificate is included in Annex $\mathrm{I}$ to the EU Administrative Procedure for
Application of Article 82 for Official Control Authority Batch Release of Immunological Veterinary Medicinal Products. There are twelve OMCLs in Europe that are able to issue OCABR Certificates, including the Polish OMCL of the NVRI which obtained EDQM attestation in 2017 (Table 4). The importance of OCABR certificates issued for vaccines based on batch release procedure has been emphasised in a publication from the German OMCL, the Paul-Ehrlich-Institut (18). Researchers analysed whether batch control is useful in the context of human influenza vaccines. It turns out that in 2006-2016, among 5,850 batches tested by the OMCL network, notifications were recorded in 32 cases. Most of them were withdrawn by the manufacturer before marketing, while in only three cases the European control laboratory reported noncompliance, which resulted in the withdrawal of 13 batches. This analysis has demonstrated the importance of the OCABR system (18).

Article 81 of Directive 2001/82/EC allows a member state to ask a Marketing Authorisation Holder for IVMP control documentation proving that control tests were carried out in accordance with the methods laid down in the marketing authorisation (MA). A goodwill agreement has been adopted by the VBRN to mutually recognise OBPR certificates between member states provided the procedure and rules codified by the network are followed.

The NVRI is the only institute in Poland that performs batch release of IVMPs. The batch control scheme is presented in Fig. 2. Until 2017, the NVRI only issued national certificates for IVMP batch release. In 2018, the NVRI issued 1,932 certificates for batch release of IVMPs, including European OBPR certificates (Table 5). The National Medicines Institute in Warsaw performs laboratory tests of medicinal products before and after their launch on the market, for their general supervision for patient safety - both in humans and animals (15). Batch release of human vaccines is conducted by the National Institute of Public Health-National Institute of Hygiene in Warsaw.

\section{Postmarketing surveillance studies of immunological veterinary medicinal products in the NVRI}

The NVRI is one of the few OMCLs in the European Union that performs testing of IVMPs that are in use on the market. According to Article 118 of the Pharmaceutical Law of 06/09/2001 and Article 1 of the Pharmaceutical Law of 19/12/2014 $(1,2)$, supervision of the quality of IVMPs on the Polish market is the responsibility of the Chief Veterinary Officer (CVO). Each year, a randomly sampled list of IVMPs selected for official quality studies is prepared by the CVO and submitted to the NVRI/OMCL. 


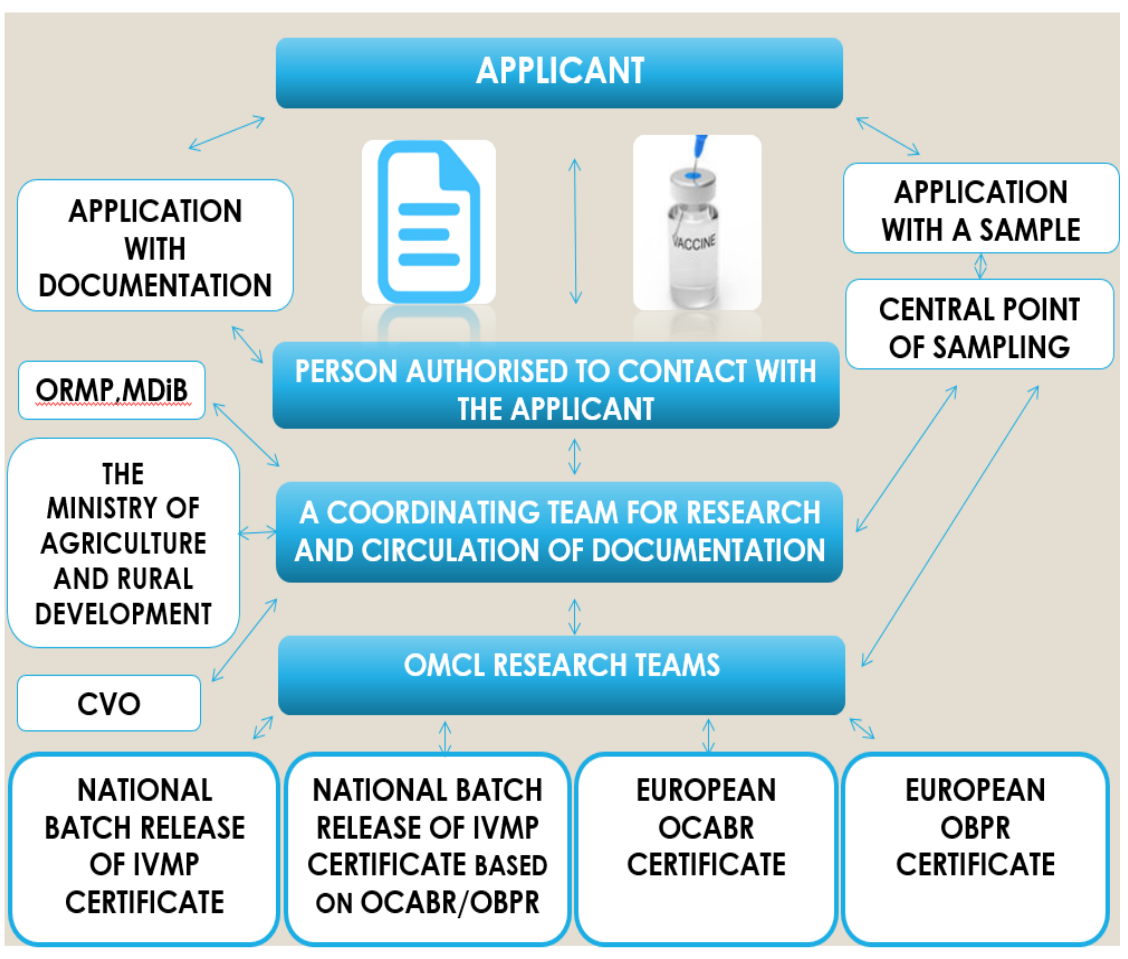

Fig. 2. Batch release control scheme

Table 4. OMCLs within the Veterinary Batch Release Network able to provide OCABR Certificates (list updated 07/09/2018)

\begin{tabular}{lll}
\hline No. & Country & Name of OMCL \\
\hline 1 & Belgium & Veterinary and Agrochemical Research Centre (CODA-CERVA) \\
\hline 2 & Czech Republic & Institute for State Control of Veterinary Biologicals and Medicines \\
\hline 3 & Finland & Finnish Food Safety Authority, Evira \\
\hline 5 & France & French National Agency for Veterinary Medicinal Products (Anses-ANMV) \\
\hline 6 & Germany & Paul-Ehrlich-Institut (PEI) \\
\hline 7 & Hungary & $\begin{array}{l}\text { National Food Chain Safety Office, Directorate for Veterinary Medicinal Products, } \\
\text { Immunological Department Biological Laboratory }\end{array}$ \\
\hline 8 & Poland & National Veterinary Research Institute \\
\hline 9 & Romania & Institute for Control of Veterinary Biological Products and Medicines \\
\hline 10 & Slovak Republic & Institute for State Control of Veterinary Biologicals and Medicaments \\
\hline
\end{tabular}

The CVO orders the Office of Registration of Medicinal Products, Medical Devices, and Biocidal Products to prepare the registration documentation regarding the selected IVMPs. Dossiers are delivered to the OMCL at the NVRI. The OMCL research teams determine the number of samples needed for testing and prepare a cost estimation of the quality testing based on the methods described in registration documentation. After approval by the CVO, the contracts to perform quality testing are signed between Regional Veterinary Inspectors and the OMCL. This activity is coordinated by the CVO. Samples are collected from veterinary wholesalers by inspectors (responsible for pharmaceutical supervision) from 16 Regional Veterinary Inspectorates, for official monitoring of the quality of IVMPs on the Polish market.

The parameters of IVMP quality PMS tests in 2010-2018 are shown in Fig. 3. The most frequent quality control tests performed on IVMPs in PMS are appearance, sterility, $\mathrm{pH}$, extractable volume, residual moisture, viscosity, virus titre, bacteria titre, and density. Results of the tests are entered to the MyLIMS database and then sent in the form of test reports and protocols to the relevant Regional Veterinary Inspectorates and to the CVO. If the results of the testing do not conform to the manufacturer's specification, the CVO decides to withdraw the IVMP from the market. In 2018, IVMPs for poultry made up the majority of the PMS studies (Fig. 4). These data 
coincide with the trend in batch control of IVMPs as the most common veterinary vaccines introduced to the Polish market are for poultry (Fig. 5). The PMS in 2018 also included IVMPs for pets $(26.9 \%)$, cattle (19.2\%), swine $(9.6 \%)$, and others. In case of non-conformity of the packaging and information leaflet to the approved template, the CVO sends this information to the MAH to correct the errors. Data from the PMS survey in 2010-2018 presented in Table 6 demonstrate that the number of IVMPs to be tested showed an increasing tendency and then remained stable. In 2018, 47 products were evaluated and there were 12 nonconformities of the leaflet/package reported and 1 nonconformity of test results.

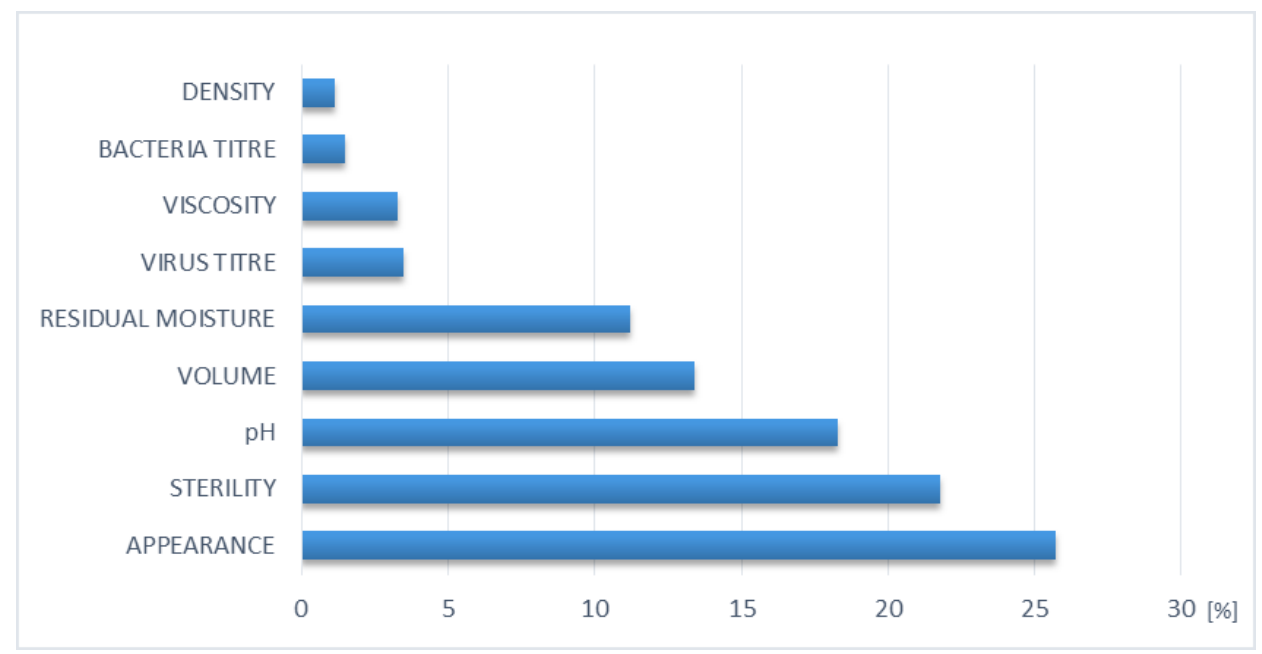

Fig. 3. The most frequently performed quality tests of IVMPs in PMS 2010-2018

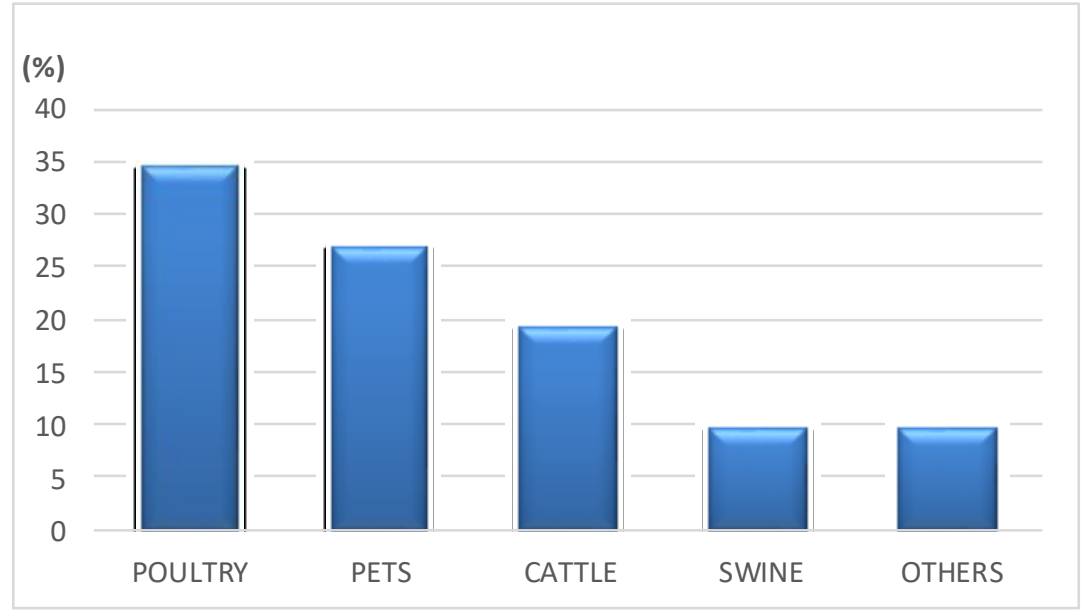

Fig. 4. Percentage of vaccines for different animal species evaluated during PMS studies in 2018

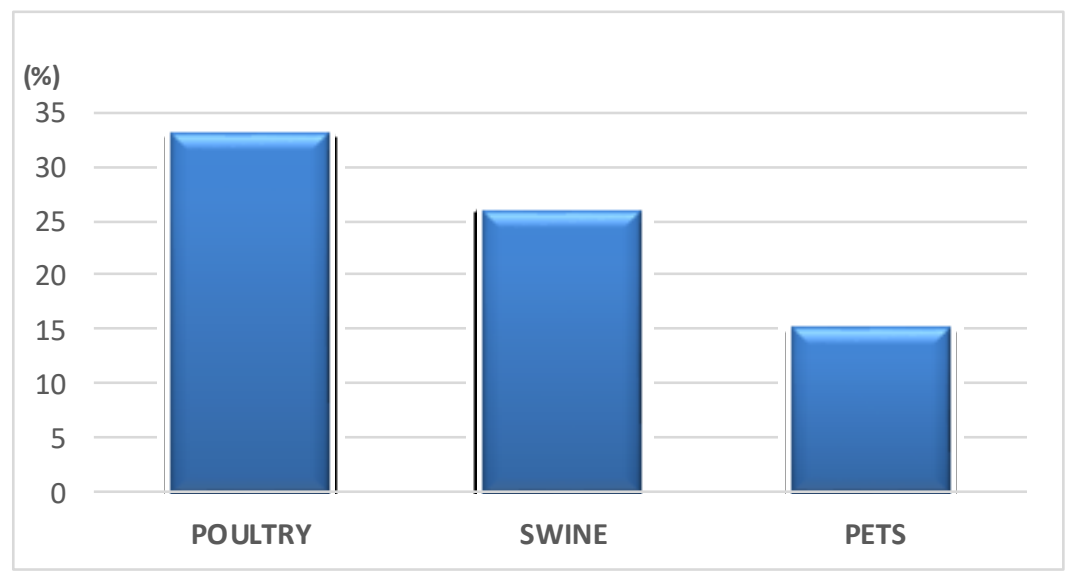

Fig. 5. Percentage of vaccines for selected animals species on the Polish market in 2018 
Table 5. The number of batch release certificates for IVMPs issued by NVRI between 2010 and 2018

\begin{tabular}{ll}
\hline Year & Number of certificates for IVMPs \\
\hline 2010 & 1,334 \\
\hline 2011 & 1,260 \\
\hline 2012 & 1,518 \\
\hline 2013 & 1,424 \\
\hline 2014 & 1,444 \\
\hline 2015 & 1,542 \\
\hline 2016 & 1,660 \\
\hline 2017 & 1,685 \\
\hline 2018 & 1,932 \\
\hline
\end{tabular}

Table 6. Results of PMS studies between 2010 and 2018

\begin{tabular}{llll}
\hline Year & $\begin{array}{l}\text { Number of samples } \\
\text { of IVMPs tested }\end{array}$ & $\begin{array}{l}\text { Non-conformity of the } \\
\text { leaflet/package }\end{array}$ & $\begin{array}{l}\text { Non-conformity } \\
\text { of test results }\end{array}$ \\
\hline 2010 & 18 & 8 & 0 \\
\hline 2011 & 12 & 15 & 0 \\
\hline 2012 & 29 & 30 & 2 \\
\hline 2013 & 35 & 19 & 5 \\
\hline 2014 & 36 & 1 & 1 \\
\hline 2015 & 42 & 5 & 2 \\
\hline 2016 & 46 & 19 & 0 \\
\hline 2017 & 50 & 15 & 1 \\
\hline 2018 & 47 & 12 & \\
\hline
\end{tabular}

\section{Conclusions}

Every year, new medicinal products are introduced to the European market, but there are also reports of side effects after administration of certain medicines. The quality control of medicinal products in Europe is supervised and performed by specialised organisations such as the EMA, EDQM, and their associated network of OMCLs (GEON). The key to the success of immunological veterinary medicinal product control was the development of a Mutual Recognition Agreement strategy, based on the introduction of OCABR and OBPR certificates. These certificates issued by any given member state should be mutually recognised by all other member states requiring OCABR/OBPR for that product. The harmonisation of pharmaceutical law in the context of official batch release provides the application of the same quality control standards throughout the European Union. The annual reporting of these medicinal control data to the EDQM allows full transparency of information for all OMCLs.

The NVRI activity described here is an example of a veterinary OMCL, which, by issuing batch release certificates for IVMPs and performing PMS tests, is a member of the powerful GEON organisation that oversees the quality of medicinal products in Europe.

Conflict of Interests Statement: The authors declare that there is no conflict of interests regarding the publication of this article.

Financial Disclosure Statement: None required.

Animal Rights Statement: None required.

\section{References}

1. Article 1 of the Pharmaceutical Law of $19 / 12 / 2014$, Journal of Laws of the Republic of Poland 2015, 0, item 28, as amended.

2. Article 118 of the Pharmaceutical Law of 06/09/2001, Journal of Laws of the Republic of Poland 2001, 126, item 1381, as amended.

3. Article 2 point 9 of the Pharmaceutical Law of $06 / 09 / 2001$, Journal of Laws of the Republic of Poland 2001, 126, item 1381, as amended.

4. Article 81 of Directive 2001/82/EC, as amended by Directive 2004/28/EC, of the European Parliament and the Council. 
5. Article 82 of Directive 2001/82/EC, as amended by Directive 2004/28/EC, of the European Parliament and the Council.

6. Chang Y., Brewer N.T., Rinas A.C., Schmitt K., Smith J.S.: Evaluating the impact of human papillomavirus vaccines. Vaccine 2009, 27, 4355-4362. doi:10.1016/j.vaccine.2009.03 .008. PMID 19515467.

7. Council of Europe: Presentation of the EDQM and its activities. 2016. https://www.youtube.com/watch?v=YWN7BsUyipc.

8. Encyclopedia Britannica: Entry on vaccines. https://www. britannica. com/science/vaccine.

9. EudraVigilance - European database of reports on suspected adverse drug reactions: Medicines in the EU. http://www.adrreports.eu/en/medicines_in_EU.html.

10. European Directorate for the Quality of Medicines \& HealthCare (EDQM): Institutional Brochure. https://www.edqm.eu/sites/ default/files/institutional-brochure-edqm.pdf.

11. European Directorate for the Quality of Medicines \& HealthCare (EDQM): Levels of collaboration within the General European OMCL Network (GEON). https://www.edqm.eu/en/Levels-ofCollaboration-within-the-OMCL-129.html.

12. European Directorate for the Quality of Medicines \& HealthCare (EDQM): Official website. https://www.edqm.eu/.

13. European Medicines Agency: Official website. https://www.ema.europa.eu/.

14. European Union: Website listing EU agencies. https://europa. eu/european-union/about-eu/agencies/ema_pl.

15. Fijałek Z.: Role of the National Medicines Institute in quality assurances and safety of medicinal products and medical devices. Przegl Med Uniw Rzeszowskiego i Narod Inst Lek w Warszawie 2010, 3, 259-270.

16. Fiore A.E., Bridges C.B., Cox N.J.: Seasonal influenza vaccines. Current Topics Microbiol Immunol 2009, 333, 43-82. doi:10.1007/978-3-540-92165-3_3. ISBN 978-3-540-92164-6. PMID 19768400

17. Guo Y., Lei K., Tang L.: Neoantigen vaccine delivery for personalized anticancer immunotherapy. Front Immunol 2018, 9, 1-8. doi: 10.3389/fimmu.2018.01499. eCollection 2018.
18. Kretzschmar E., Muckenfuss H., Pfleiderer M.: Official batch control of influenza vaccines: Is it still useful? Vaccine 2018, 36, 2364-2370.

19. Liesegang T.J.: Varicella zoster virus vaccines: effective, but concerns linger. Canadian J Ophthalmol 2009, 44, 379-384. doi:10.3129/i09-126. PMID 19606157.

20. Markey K., Douglas-Bardsley A., Hockley J., Le Tallec D., Costanzo A.: Calibration of pertussis toxin BRP batch 1 in a standardised $\mathrm{CHO}$ cell-based clustering assay. Pharmeur Bio Sci Notes 2018, 112-123.

21. Matejtschuk P., Duru C., Bristow A.F., Burns C.J., Cowper B., Daas A., Costanzo A.: Establishment of detection antibodies BRRs batch 5 for in vitro potency assay of hepatitis A vaccines by ELISA. Pharmeur Bio Sci Notes 2019, 11-26.

22. Medycyna Praktyczna: Klasyfikacja i skład szczepionek (Classification and composition of vaccines (in Polish)). https://www.mp.pl/pacjent/choroby-zakazne/szczepienia/158371, klasyfikacja-i-sklad-szczepionek.

23. Morgeaux S., Koy A., Manniam I., Regourd E., Variot P., Milne C.: Establishment of detection antibodies BRRs batch 5 for in vitro potency assay of hepatitis A vaccines by ELISA. Pharmeur Bio Sci Notes 2019, 1-10.

24. Sass J., Becker K., Ludmann D., Pantazoglou E., Dewenter H., Thun S.: Intercoder reliability of mapping between pharmaceutical dose forms in the German Medication Plan and EDQM Standard Terms. Stud Health Technol Inform 2018, 247, 845-849.

25. United States Centers for Disease Control and Prevention: A CDC framework for preventing infectious diseases: Sustaining the Essentials and Innovating for the Future. https://www.cdc.gov/ddid/framework.html.

26. United States Department of Health and Human Services: Types of vaccines. https://www.vaccines.gov/basics/types/index.html.

27. Wanko R., Unkelbach U.: European network of official medicines control laboratories: international OMCL Working Group combating counterfeit and other illegal medicines. Bundesgesundheitsblatt Gesundheitsforschung Gesundheitsschutz 2017, 60, 1221-1227. doi: 10.1007/s00103-017-2625-7. 